УДК 330.342

\title{
Е.Б. Хоменко
}

\section{ЦИФРОВАЯ ЭКОНОМИКА: АКТУАЛЬНЫЕ ВОПРОСЫ ТЕОРИИ И ПРАКТИКИ}

Современный этап развития экономики в мировой и российской экономической науке и хозяйственной практике принято называть цифровой экономикой. Цифровизация внесла существенные коррективы во все сферы жизни общества, вызвав научную дискуссию о сущности и содержании таких понятий, как «цифровая экономика», «цифровой сектор экономики», «цифровая грамотность». В связи с тем, что в настоящее время идет пероральное развитие теории и практики цифровой экономики, и в науке и в практической деятельности в употреблении данных терминов присутствует масса разночтений, что требует дополнительных научных исследований в области систематизации концептуальных положений теории цифровой экономики. Данная работа осложняется междисциплинарным характером рассматриваемых вопросов, имеющих экономические, технические, социально-культурные аспекты, и в связи с этим сложностью сближения позиций представителей различных наук.

В статье проанализированы истоки формирования теории цифровой экономики, основные подходы к определению сущности понятия «цифровая экономика»; рассмотрен взаимодополняющий характер изучения цифровой экономики как современной экономической среды - этапа развития информационной экономики, и как сферы применения цифровых технологий. Автором обосновано мнение о том, что в условиях цифровой экономики принципиальное значение приобретает приведение в соответствие новым реалиям содержания образовательных программ университетов, так как особое значение приобретает формирование у будущих специалистов цифровой грамотности и экономического образа мышления как основы решения профессиональных задач в цифровой среде.

Ключевые слова: цифровая экономика, цифровой сектор экономики, цифровые технологии, информационная экономика, цифровая грамотность.

DOI: 10.35634/2412-9593-2021-31-1-45-52

В современной экономической науке и хозяйственной практике понятия, включающие слова «цифровая», «цифровизация», становятся все более применяемыми для характеристики состояния и направления развития экономической среды. Однако, теоретики и практики, экономисты и инженеры, исследователи теоретических и прикладных аспектов развития экономических систем определяют широкий круг понятий, производных от слова «цифра», весьма неоднозначно. Популяризации данной терминологии способствовало ее использование в исследованиях международных организаций, в частности Мирового банка, Международного валютного фонда, Организации экономического сотрудничества и развития, национальных программах и средствах массовой информации. Кроме того, практическое значение цифровизации в обществе возросло вследствие распространения в мире новой коронавирусной инфекции, так как из-за пандемии и последующего локдауна актуализировалось использование цифровых технологий во всех сферах жизнедеятельности людей. Тем не менее к большей определенности понятийного аппарата цифровой экономики, его массовое распространение не привело, а, наоборот, число разночтений и новых интерпретаций только существенно увеличилось. Данные проблемы обусловлены, на наш взгляд, в первую очередь, особенностями сфер применения терминов: экономическая, техническая, социально-культурная; во-вторых, влиянием используемого подхода к изучению вопроса с точки зрения масштаба раскрытия тематики (налагаемых ограничений) - широкий / расширенный / узкий.

Таким образом, дать какое-либо одно исчерпывающее определение каждого из понятий, объединенных под зонтичным термином «цифровая экономика», которое имело бы содержательное единство и устроило представителей различных наук, задача в настоящее время сложно выполнимая. Однако критически важно исключить подмену понятий, грамотно расставить акценты, например, при разграничении экономической и технической составляющей цифровой экономики, определить аспекты, понимание сущности которых важно в образовательных целях и в современных условиях имеет высокое общественное значение для практики подготовки специалистов с высшим образованием.

Понятие «цифровая экономика» как аналог английского словосочетания «digital economy» достаточно новое. Оно вошло в научный и практический оборот лишь четверть века назад, с выходом в свет работ канадского экономиста Дона Тапскотта «Цифровая экономика» (1994 г.) и американского экономиста Николаса Негропонте «Цифровое существование» (1995 г.). Авторы подчеркивают прин- 
ципиальное отличие надвигающейся эпохи цифровизации глобальной экономики, в которой решающее значение имеет возможность существенного сокращения трансакционных издержек в результате внедрения цифровых технологий (Д. Тапскотт) [1]; перехода к экономической деятельности, преимущественно направленной на обработку битов и создание программных кодов, взамен преобразования материальных ресурсов в физический продукт (Н. Негропонте) [2].

За два десятилетия XXI в. сеть Интернет прочно вошла в повседневную жизнь человека; произошло радикальное изменение производственных процессов на основе внедрения цифровых технологий; динамичное развитие мобильной связи принципиально изменило коммуникативные возможности людей; традиционная аналоговая экономика приросла виртуальной составляющей, а работа в режиме online стала одной из альтернатив организации рабочего места; новые рынки и новый цифровой продукт привели к созданию новых моделей успешного бизнеса.

В настоящее время мировая и отечественная экономическая наука, государственное управление и хозяйственная практика накопили достаточный теоретический, управленческий и практический опыт становления цифровой экономики, который требует осмысления и систематизации, и такая работа в экспертном сообществе сегодня достаточно активно ведётся [3].

Так, 3. Басаев подчеркивает два теоретических аспекта в определении содержания цифровой экономики. По его мнению, первый связан с воспроизводством информационных технологий и обусловлен четвертой промышленной революцией. В основе второго аспекта «новые методы обработки, хранения и передачи данных... весь спектр онлайн-бизнеса» [4]. Автор отмечает, что внедрение новых технологий приведет трансформации состава цифровой экономики в сторону его расширения и, соответственно, к изменению трактовки ее содержания.

С методологической позиции интересно исследование содержания цифровой экономики, выполненное Ю.В. Белоусовым и О.И. Тимофеевой [5]. Ученые выделяют два методологических подхода к рассмотрению дефиниции цифровой экономики. В основе первого подхода - критерий отраслевой принадлежности, в соответствии с которым выделяют виды экономической деятельности, соответствующие цифровой экономике. Данный подход удобен для использования при оценке вклада цифровой экономики в основные макроэкономические показатели. Однако, состав видов экономической деятельности, которые могут быть отнесены к цифровой экономике, является предметом научной дискуссии. Это обусловлено тем, что понятие охватывает лишь часть экономики, которая может быть названа «цифровой» или «цифровым сектором», а также остается без ответа вопрос о критерии отнесения отрасли к цифровой или к традиционной экономике. С позиции второго подхода цифровая экономика - это новый этап в развитии экономики [6], соответствующий формирующемуся шестому технологическому укладу, которому присуще возрастание значимости когнитивных технологий и творческого труда, ориентированного на производство интеллектуального информационного продукта [7]. Ю.В. Белоусов и О.И. Тимофеева особо отмечают тот факт, что в дефиниции «цифровая экономика» слово «экономика» является родовым, а ведущие процессы в цифровой экономике - это создание цифровых систем управления и их применение в производстве [5].

Рассуждая о цифровой экономике, исследователи нередко смещают «центр тяжести» в ее изучении в сторону видовой составляющей, акцентируя внимание на цифровом аспекте. Например, Г.В. Лепеш указывает, что «под термином "цифровая экономика" сегодня сосуществуют два понятия». При этом автор подходит к их разграничению сугубо с технократической позиции - масштаба применения цифровых технологий в производственной деятельности: 1) производство с использованием цифровых технологий (расширенное понимание); производство электронных товаров и услуг (классическое понимание). Кроме того, автор называет цифровые компьютерные технологии важной частью цифровой экономики, а уровень «цифровизации» реальной экономики зависимым от уровня развития цифровой экономики [8], которая фактически приравнивается к электронной коммерции.

Недостаточно четко определяются границы цифровой экономики и зарубежными исследователями, в частности Р. Клинг и Р. Лэмб выделяют в ее составе цифровые продукты и услуги, смешенные цифровые продукты и услуги, услуги или производство товаров, зависящие от ИТ, производители сетевого оборудования и персональных компьютеров, а также фирмы, занимающиеся ИТ-консалтингом [9]. При таком подходе, на наш взгляд, теряется научность и практическая значимость термина «цифровая экономика», так как в нем утрачивается содержательная экономическая составляющая. Однако, именно данная трактовка термина «цифровая экономика» в настоящее время популяризируется средствами массовой информации со ссылкой на положения Национального проекта «Цифровая экономи- 
ка Российской Федерации» о значимости создания информационно-телекоммуникационной инфраструктуры, разработки отечественного программного обеспечения, преобразования приоритетных отраслей экономики и социальной сферы путем внедрения цифровых технологий и платформенных решений и др. [10].

Не отрицая важность решения задач в области разработки и внедрения цифровых технологий, обратим внимание на одну из национальных целей развития РФ, представленных в тексте Указа Президента РФ: содействовать «вхождению Российской Федерации в число пяти крупнейших экономик мира, обеспечение темпов экономического роста выше мировых при сохранении макроэкономической стабильности» [10]. Конечно, достижение этой цели в условиях применения устаревшей техники и технологий невозможно, но и абсолютизировать их значение в цифровой экономике некорректно, так как важно обеспечить сбалансированное развитие необходимого ресурсного обеспечения для эффективного решения поставленных задач.

В «Стратегии развития информационного общества в Российской Федерации на 2017-2030 годы» подчеркивается в качестве ведущего фактора производства информация, определяемая как данные в цифровом виде [11]. В этом контексте для характеристики современной экономики развитых стран наиболее применимым является понятие «информационная экономика», которой сегодня присущи следующие черты: Во-первых, сформирован ИТ-сектор, который опирается на цифровые технологии, и представлен секторами: производства ИКТ, знаний, коммуникаций. Во-вторых, наблюдается интеграция реального и виртуального секторов экономики, расширение возможностей для выполнения полезных действий в реальном секторе через виртуальный. В-третьих, создана и функционирует цифровая инфраструктура, обеспечивающая благоприятные условия для доступа субъектов экономики к информационным ресурсам, включая доступ к государственным, образовательным, медицинским, консалтинговым и иным услугам, а также возможности для реализации виртуальных бизнес-проектов. В-четвертых, в системах управления на микро- и макроуровнях возрастает значение управления большими данными.

Этапы развития теории информационной экономики

\begin{tabular}{|c|c|c|}
\hline Этап & Характеристика этапа & Авторы \\
\hline $\begin{array}{l}\text { 1. Накопление и систематизация } \\
\text { данных об информационном про- } \\
\text { изводстве (50-60-е гг. XX в.) }\end{array}$ & $\begin{array}{l}\text { Определение предпосылок и диагностика } \\
\text { проблем информатизации производства, } \\
\text { разработка вариантов их решения }\end{array}$ & $\begin{array}{l}\text { М. Браун, } \\
\text { Э. Дэнисон, } \\
\text { Дж. Кендрик, } \\
\text { Д. Сахал и др. }\end{array}$ \\
\hline $\begin{array}{l}\text { 2. Зарождение теории информаци- } \\
\text { онной экономики (70-сер. 80-х гг. } \\
\text { XX в.) }\end{array}$ & $\begin{array}{l}\text { Формирование новых подходов к производ- } \\
\text { ству научно-технической информации как к } \\
\text { самостоятельной отрасли хозяйства и к ис- } \\
\text { следованию экономической эффективности } \\
\text { производства информации }\end{array}$ & $\begin{array}{l}\text { Й. Масуда, } \\
\text { Д. Белл, } \\
\text { Р. Н. Лерера, } \\
\text { Л. Э. Миндели, } \\
\text { Э. Робертс и др. }\end{array}$ \\
\hline $\begin{array}{l}\text { 3. Расширение предметной облас- } \\
\text { ти теории информационной эко- } \\
\text { номики (сер. 80-х гг. - сред. 90-х } \\
\text { гг. ХХ в.) }\end{array}$ & $\begin{array}{l}\text { Разработка институционально- } \\
\text { эволюционного подхода к изучению про- } \\
\text { блем информационной экономики. Разра- } \\
\text { ботка основных положений к теории нацио- } \\
\text { нальной инновационной системы }\end{array}$ & $\begin{array}{l}\text { К. Фримен, } \\
\text { Р. Нельсон, } \\
\text { Б. Лундвалл и др. }\end{array}$ \\
\hline $\begin{array}{l}\text { 4. Формирование теории сетевой } \\
\text { организации информационных } \\
\text { структур (втор. половина 90-х гг. } \\
\text { XX в. по ср. 2000) }\end{array}$ & $\begin{array}{l}\text { Становление теоретико-методологических } \\
\text { основ софтизации экономики и создания } \\
\text { сетевой организации информационных } \\
\text { структур }\end{array}$ & $\begin{array}{l}\text { Э. Тоффлер, } \\
\text { С. А. Дятлов, } \\
\text { В. Л. Иноземцев, } \\
\text { В. И. Маевский и др. }\end{array}$ \\
\hline $\begin{array}{l}\text { 5. Разработка теоретических по- } \\
\text { ложений о цифровой трансформа- } \\
\text { ции экономики как результата } \\
\text { информационной революции и } \\
\text { процесса глобализации экономики } \\
\text { (втор. половина 90-х гг. XX в. по } \\
\text { наст. время) }\end{array}$ & $\begin{array}{l}\text { Исследование процесса перехода от индуст- } \\
\text { риальной экономики к цифровой, базирую- } \\
\text { щейся на ИКТ, эволюционного развития } \\
\text { цифровой экосистемы и возможностей пе- } \\
\text { рехода к «творческой экономике», где фор- } \\
\text { мируется гибридная «виртуально-реальная» } \\
\text { среда }\end{array}$ & $\begin{array}{l}\text { Д. Тапскотт, } \\
\text { Н. Негропонте, } \\
\text { Р. Клинг, } \\
\text { Р. Лэмб, } \\
\text { Т. Л. Мезенбург, } \\
\text { В. П. Куприяновский, } \\
\text { А. В. Кешелава и др. }\end{array}$ \\
\hline
\end{tabular}

Источник: [12. С. 12-13]. 
Именно необходимость работы с большими данными, их сбор, систематизация и оценка, определяют особенность нового этапа в развитии информационной экономики, который, по нашему мнению, может быть обозначен как цифровая экономика (см. табл.).

Рост информационной емкости экономики, повышение эффективности и снижение стоимости информационно-коммуникационных технологий, а также высокий уровень доступности цифровой инфраструктуры сегодня являются драйверами развития национальных экономик. Это является результатом цифровой трансформации в обществе на основе роста объемов информации, безграничных возможностей использования Интернет-площадок, и наличия конкурентного потенциала у стартапов за счет внедрения новых цифровых технологий и использования возможностей цифровых платформ.

Тем не менее в настоящее время еще не сложилось единой научной терминологии, научного языка, на котором были бы сформулированы концепции экономики, раскрывающие ее особенности в условиях динамично меняющихся потребностей людей, появления новых форм коммуникаций, внедрения цифровых технологий, открытых инноваций и стремительной диффузии знаний.

Таким образом, понятие «цифровая экономика» применяется для характеристики современного этапа развития экономики наряду с терминами «экономика знаний», «инновационная экономика», «новая экономика». Содержание перечисленных понятий определяется авторами по-разному, так как в каждом случае выделяется определенный аспект исследования, но эти термины применяются для характеристики одного и того же периода развития экономики.

Новый технологический уклад, соответствующий цифровой трансформации, функционирует на основе принципа постоянного улучшения. Это требует применения новых бизнес-моделей как способа схематизации всех процессов в организации и эффективного механизма использования новых технологий. При этом значительный масштаб бизнеса в современных условиях не гарантирует ему успешного развития, тогда как небольшие компании - производители интеллектуального информационного продукта - компании «единороги» зачастую демонстрируют экспоненциальный рост. Экспоненциальный характер роста становится возможным благодаря тому, что новые цифровые технологии позволяют увеличить скорость обработки информации при снижении цены материальных носителей информации.

К компаниям «единорогам» относят фирмы с оценочной стоимостью больше миллиарда долларов США, оценка осуществляется на основе определения готовности инвесторов платить за доли в компании, но данные о показателях частная компания может не раскрывать, поэтому к ним нужно относиться с определенной долей осторожности. Данные компании реализуют в своей деятельности принцип совместного потребления (sharing economy), то есть реализация возможности делиться между собой товарами, знаниями и временем. Сегодня к таким «единорогам» относят компании, предоставляющие жилье (Airbnb), транспорт (Uber, Getaround, Яндекс Такси, Делимобиль), спортивный инвентарь (Spinlister), еду (LeftoverSwap) и др. Реализация принципа совместного потребления через цифровые платформы сокращает информационную асимметрию, упрощая доступ экономических субъектов к рынку, способствуя позиционированию их услуг и повышению репутации. Выгода владельцев недвижимости или автомобилей здесь очевидна. Если имущество используется собственником лишь на 10-15\%, то оно может приносить пользу другим субъектам в течение оставшихся 85-90 \% времени. В результате люди начинают делиться через сеть тем, что для них ничего не стоит, но может приносить доход и быть полезно и ценно для других [13].

\begin{tabular}{|c|c|c|}
\hline \multicolumn{3}{|c|}{ Основные идеи концепции Индустрия 4.0} \\
\hline «Интернет вещей» & «Большие данные» & «Киберфизические системы» \\
\hline $\begin{array}{l}\text { - концепция оснащения вещей } \\
\text { встроенными технологиями } \\
\text { для взаимодействия друг с } \\
\text { другом или с внешней средой }\end{array}$ & $\begin{array}{l}\text { - совокупность инструментов } \\
\text { обработки больших объемов } \\
\text { данных для получения резуль- } \\
\text { татов, воспринимаемых чело- } \\
\text { веком }\end{array}$ & $\begin{array}{l}\text { - концепция взаимодействия } \\
\text { датчиков, оборудования и ин- } \\
\text { формационных систем друг с } \\
\text { другом, самонастройки и адап- } \\
\text { тации к изменениям }\end{array}$ \\
\hline
\end{tabular}

Рис. 1. Характеристика основных идей концепции Индустрия 4.0 
Цифровая экономика в сфере материального производства наиболее ёмко представлена в немецкой концепции Индустрия 4.0 [7] (рис. 1).

Соединение перечисленных концептуальных положений в рамках единой концепции Индустрия 4.0 делает ее устойчивым фундаментом для развития промышленного производства, что позволяет рассматривать ее в качестве основы для внедрения принципов «умного производства». Важно подчеркнуть, что цифровые технологии позволяют сформировать среду, способствующую повышению скорости обмена идеями между учеными, разработчиками, производителями и потребителями цифровых продуктов, что позволяет расширить круг участников процесса их создания, предоставляя возможности для внесения корректировок и совершенствования с учетом стратегических задач развития производства.

Таким образом, цифровизация экономики видоизменяет условия жизнедеятельности человека. С одной стороны, это проявляется во многократном расширении возможностей для получения новых знаний, формирования новых навыков и получения новых профессий [14]. С другой стороны, исследователи подчеркивают, что обратной стороной цифровизации является эффект технологической безработицы, в результате влияния которого в первую очередь пострадают работники, обладающие средней квалификацией, именно их рабочие места экономически эффективно полностью автоматизировать [15]. Эксперты прогнозируют, что в мировой экономике к 2030 г. до 50 \% операций в различных сферах экономической деятельности могут быть автоматизированы (рис. 2) [16]. Это сопоставимо с промышленной революцией XVIII-XIX вв.

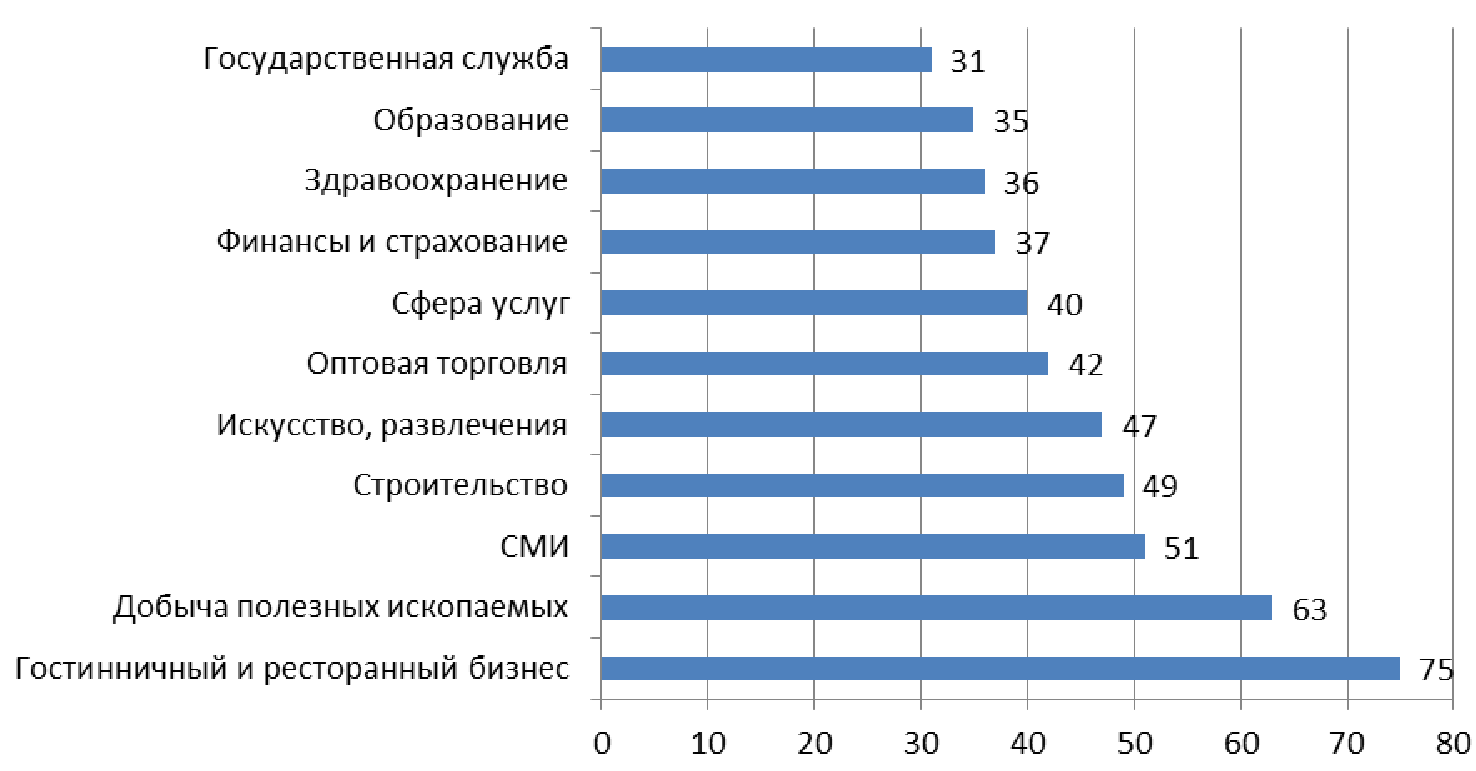

Рис. 2. Прогнозируемый уровень автоматизации видов экономической деятельности, \%

Важно подчеркнуть, что при наличии рисков сокращения количества рабочих мест в экономике вследствие автоматизации, практика показывает, что в результате цифровизации вместо каждого утраченного рабочего места создается 3,1 новое [17].

Таким образом, чтобы соответствовать требованиям радикально изменившейся гибридной экономической среды [18], человек эпохи цифровизации должен быть готов вносить в свою жизнь кардинальные изменения, постоянно обновляя свои знания. Это необходимо не только в силу влияния цифровой трансформации на сферу производства, но и в целях адаптации к принципиальным изменениям в социальной сфере. В результате значимость совершенствования системы образования сегодня становится весьма актуальной социально-экономической задачей. Многие ученые отмечают сегодня важность формирования базовых цифровых навыков, образующих цифровую грамотность, которую упрощенно можно рассматривать как способность отбирать информацию из различных источников, оценивать ее содержание, систематизировать по различным основаниям, а также решать задачи, требующие работы с незнакомым контекстом [19]. В настоящее время возрастает спрос не только и не столько на специалистов в сфере ИКТ, сколько на специалистов в других сферах, обладающих 
базовыми ИКТ-навыками, которые позволяют эффективно использовать цифровые технологии в конкретной профессиональной деятельности. Однако, говоря о необходимости подготовки будущих специалистов в области цифровой грамотности как об условие соответствия их компетенций требованиям цифровой экономики, по нашему мнению, следует обратить внимание на значимость формирования экономического мышления, соответствующего современным реалиям. Наличие только технических навыков даже на достаточно высоком уровне не подготовит будущего специалиста к восприятию современных экономических реалий, трансформация которых в настоящее время принципиально изменяет экономические отношения в обществе.

Таким образом, образовательные программы бакалавриатов неэкономических направлений подготовки, на наш взгляд, должны предусматривать изучение основ цифровой экономики не только с технических, но и с социально-экономических позиций. Это необходимо в целях формирования мировоззрения молодых людей, их готовности к участию в цифровой экономике как потребителя, предпринимателя, наемного работника, члена общества, умеющего использовать новые возможности и принимать решения с учетом рисков цифровой среды [20]. Задачами изучения основ цифровой экономики, следовательно, должны стать:

- формирование основ современного экономического мышления, представлений о способах поиска, критического анализа и синтеза информации в условиях цифровой экономики;

- приобретение знаний о существующих в России тенденциях, преимуществах, рисках и перспективах развития цифровой экономики;

- изучение особенностей, обусловленных развитием цифровой экономики, в государственном управлении, хозяйственной практике, в распределении и потреблении материальных благ и услуг.

Для решения перечисленных выше задач раскрытие содержания цифровой экономики может быть реализовано посредством рассмотрения ряда актуальных в настоящее время вопросов теории и практики цифровой экономики, в частности:

- цифровая экономика как модель отношений между людьми, совместимая с цифровыми технологиями;

- влияние цифровой экономики на образ жизни людей;

- тенденции, преимущества и перспективы развития цифровой экономики;

- роль государства в развитии процессов цифровизации в современной экономике;

- риски процессов цифровизации экономики и способы их снижения.

В заключение хотелось бы подчеркнуть, что в современных условиях, когда цифровая экономика уже является не прогнозируемым вектором развития общества, а объективной реальностью (в одних секторах экономики более очевидной и других - только нарождающейся), игнорировать необходимость перемен как в производстве, так и в социальной сфере стало невозможным. При этом особое значение приобретает преодоление консервативного подхода в системе образования, так как именно человек, его творческие способности, интеллект, критическое мышление и умение принимать решения с учетом экономических реалий цифровой среды, являются фундаментом для успешной реализации человеком своих компетенций как в профессиональной деятельности, так и на бытовом уровне.

\section{СПИСОК ЛИТЕРАТУРЫ}

1. Tapscott D. The Digital Economy: Promise and Peril In The Age of Networked Intelligence. McGrawHill; 1995. $342 \mathrm{p}$.

2. Negroponte Nicholas. Being Digital. New York: Alfred A. Knopf; 1995. 243 p.

3. Bukht R., Heeks R. Defining, conceptualising and measuring the digital economy. The University of Manchester. Global Development Institute. Working Paper Series. 2017. № 68. URL: http://hummedia.manchester.ac.uk/ institutes/gdi/publications/workingpapers/di/di_wp68.pdf/.

4. Басаев 3.В. Цифровизация экономики: Россия в контексте глобальной трансформации // Мир новой экономики. 2018. №4. С. 32-38. URL: https://wne.fa.ru/jour/article/view/206/198.

5. Белоусов Ю.В., Тимофеева О.И. Методология определения цифровой экономики // Мир новой экономики. 2019. №4. C. 79-89. URL: https://wne.fa.ru/jour/article/view/237/228.

6. Никитенкова М. А. Информационная структура США: государство и рынок. М.: Academia, 2009. 304 c.

7. Абдикеев Н.М. Технологии когнитивного менеджмента в цифровой экономике // Мир новой экономики. 2017. №3. C. 24-28. URL: https://wne.fa.ru/jour/article/view/133/134.

8. Лепеш Г.В. Экономика цифровая и реальная // TTПС. 2017. № 4 (42). С. 3-5. URL: https://cyberleninka.ru/ article/n/ekonomika-tsifrovaya-i-realnaya. 
9. Kling R., Lamb R. IT and Organizational Change in Digital Economies. Understanding the Digital Economy / E. Brynjolfsson, B. Kahin (eds). Cambridge: MIT Press. 2000. P. 295-324.

10. Национальный проект «Цифровая экономика Российской Федерации» / утв. Указом Президента РФ от 7 мая 2018 г. № 204 «О национальных целях и стратегических задачах развития Российской Федерации на период до 2024 года». URL: https://rg.ru/2018/05/08/president-ukaz204-site-dok.html.

11. Стратегия развития информационного общества в Российской Федерации на 2017-2030 годы / утв. Указом Президента РФ от 9 мая 2017 г. № 203. URL: https://sudact.ru/law/ukaz-prezidenta-rf-ot-09052017-n-203/ strategiia-razvitiia-informatsionnogo-obshchestva-v/.

12. Хоменко Е.Б. Государственная поддержка малого предпринимательства в условиях цифровой экономики: монография / Е.Б. Хоменко, И.В. Матвеева, Л.А. Ватутина. М.: РУСАЙНС, 2020.170 с.

13. Головецкий Н.Я., Гребеник В.В. Фундаментальные основы экономики совместного потребления // Вестн. Московского ун-та имени С.Ю. Витте. Серия 1: Экономика и управление. 2017. №4 (23). С. 21-26. URL: https://cyberleninka.ru/article/n/fundamentalnye-osnovy-ekonomiki-sovmestnogo-potrebleniya.

14. Семячков К.А. Цифровая экономика и ее роль в управлении современными социально-экономическими отношениями // Современные технологии управления. № 8 (80). URL: https://sovman.ru/article/8001/.

15. Головенчик Г. Теоретические подходы к определению понятия «цифровая экономика» // Наука и инновации. 2019. №2. С. 40-45. URL: http://innosfera.by/images/temp/1-2.19.pdf.

16. Борисова Е.С., Комаров А.В. Современный рынок труда в условиях становления и развития цифровой экономики // Наука. Общество. Оборона. 2019. № 3 (20). URL: https://www.noo-journal.ru/nauka-obshestvooborona/2019-3-20/article-0197-1/.

17. Bukht R., Heeks R. Defining, Conceptualising and Measuring the Digital Economy // International Organisations Research Journal. Vol. 13, № 2. 2018. P. 143-172.

18. Введение в «Цифровую» экономику / А.В. Кешелава В.Г. Буданов, В.Ю. Румянцев и др.; под общ. ред. А.В. Кешелава; гл. «цифр.» конс. И.А. Зимненко. ВНИИГеосистем, 2017. 28 с.

19. Куприяновский В.П., Сухомлин В.А., Добрынин А.П., Райков А.Н., Шкуров Ф.В., Дрожжинов В.И., Федорова Н.О., Намиот Д.Е. Навыки в цифровой экономике и вызовы системы образования // International Journal of Open Information Technologies. 2017. №1. C. 19-25. URL: https://cyberleninka.ru/article/n/navyki-v-tsifrovoyekonomike-i-vyzovy-sistemy-obrazovaniya.

20. Хоменко Е.Б. Педагог настоящего и будущего: формирование компетенций в сфере финансовой грамотности и цифровой экономики // Ломоносовские чтения - 2020. Секция экономических наук. «Экономическая повестка 2020-х годов»: сб. тез. выступлений. М.: Экономический факультет МГУ имени М. В. Ломоносова, 2020. C. 761-763.

Поступила в редакцию 15.01.2021

\begin{abstract}
Хоменко Екатерина Борисовна, доктор экономических наук, доцент, заведующий кафедрой финансов, учёта и математических методов в экономике ФГБОУ ВО «Удмуртский государственный университет»

426034, Россия, г. Ижевск, ул. Университетская, 1

E-mail: fin@inem.uni.udm.ru
\end{abstract}

\title{
E.B. Khomenko \\ THE DIGITAL ECONOMY: TOPICAL ISSUES OF THEORY AND PRACTICE
}

\section{DOI: $10.35634 / 2412-9593-2021-31-1-45-52$}

The modern stage of economic development in world and Russian economic science and master practice is commonly called the digital economy. Digitalization had made significant adjustments to all spheres of society, sparking a scientific debate on the substance and content of such concepts as "digital economy", "digital sector of the economy", "digital literacy". Due to the fact that the theory and practice of digital economy are currently being orally developed, there are a lot of differences in the use of these terms in science and practice, which requires additional scientific research in the field of systematizing the conceptual provisions of the theory of digital economy. This situation is complicated by the multidisciplinary nature of the issues under consideration, which have economic, technical, socio-cultural aspects and, in that connection, by the difficulty of bringing together representatives of different sciences.

The article analyzes the origins of the formation of the theory of digital economy, the main approaches to determining the essence of the concept of "digital economy", considers the complementary nature of the study of digital economy as a modern economic environment - a stage of the development of the information economy, and as a sphere of application of digital technologies. The author substantiates the opinion that in the context of the digital economy, bringing into line with the new realities of the content of university educational programs is of fundamental importance, since the 
formation of a digital literacy and economic way of thinking among future specialists as the basis for solving professional problems in the digital environment takes on special importance.

Keywords: digital economy, digital sector of economy, digital technologies, information economy, digital literacy.

Received 15.01.2021

Khomenko E.B., Doctor of Economics, Head of Department of Finance, Accounting and Mathematical Methods in Economics

Udmurt State University

Universitetskaya st., 1, Izhevsk, Russia, 426034

E-mail: fin@inem.uni.udm.ru 